\section{latrogenic radial arteriovenous fistula}

A 62-year-old female underwent successful primary percutaneous coronary intervention for an acute anterior wall myocardial infarction via the right radial artery access. The patient presented 3 months later for a routine follow-up. There was a dilated superficial vein at the level of the distal right radial artery, with a palpable thrill at the access site (figure 1A). Subsequent Doppler ultrasound imaging demonstrated a radial arteriovenous fistula with a neck of $2 \mathrm{~mm}$ (figure $1 \mathrm{~B}$; see online supplementary video 1). The brachial angiography showed a right radial artery to venous fistula with multiple collateral veins (figure 1C; see online supplementary video 2 ). The patient was managed conservatively as she was asymptomatic, and the shunt was haemodynamically insignificant.

Radial artery access is currently being routinely used for cardiac catheterisation because of the lower risk of vascular complications and early patient ambulation. The common access

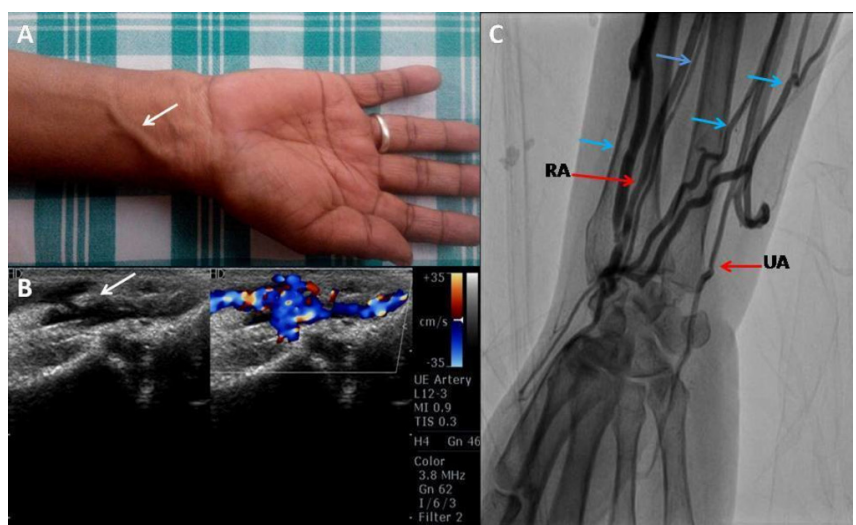

Figure 1 (A) Dilated vein (arrow) over the distal right forearm. (B) Colour Doppler imaging showing a radial arteriovenous fistula (arrow). (C) Selective brachial artery angiography showing a radial arteriovenous fistula with multiple venous collaterals (blue arrows indicate vein). RA, radial artery; UA, ulnar artery. site complications observed are radial artery spasm, haematoma and reduced or absent radial pulse. Arteriovenous fistula is a well-recognised complication after cardiac catheterisation via the femoral or brachial approach, but it is extremely rare in radial artery access-based procedures. ${ }^{1}$ This is because only small veins are present in the vicinity of the radial artery. Unlike femoral arteriovenous fistulas, there are no studies evaluating the risk factors for developing radial arteriovenous fistulas. The use of ultrasound-guided radial artery cannulation may minimise the risk of an arteriovenous fistula. Radial arteriovenous fistula can be managed conservatively in the absence of symptoms and haemodynamically insignificant shunt. Invasive treatment options include percutaneous closure of fistula and surgical correction. $^{2}$

\section{Nagaraja Moorthy, ${ }^{1}$ Rajiv Ananthakrishna ${ }^{2}$}

${ }^{1}$ Department of Cardiology, Sri Jayadeva Institute of Cardiovascular Sciences and Research, Bangalore, Karnataka, India

${ }^{2}$ Department of Cardiology, Sri Jayadeva Institute of Cardiovascular Sciences and Research, Bangalore, Karnataka, India

\section{Correspondence to Dr Rajiv Ananthakrishna; rajiva.ms@gmail.com}

Contributors Both the authors have contributed equally to the patient evaluation and write-up of the manuscript.

Competing interests None declared.

\section{Patient consent Obtained.}

Ethics approval Sri Jayadeva Institute of Cardiovascular Sciences and Research. Provenance and peer review Not commissioned; internally peer reviewed.

(c) Article author(s) (or their employer(s) unless otherwise stated in the text of the article) 2017. All rights reserved. No commercial use is permitted unless otherwise expressly granted.

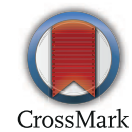

To cite Moorthy N, Ananthakrishna R. Heart Asia 2017;9:1.

Heart Asia 2017;9:1. doi:10.1136/heartasia-2017-010963

\section{REFERENCES}

1. Bhat T, Teli S, Bhat $\mathrm{H}$, et al. Access-site complications and their management during transradial cardiac catheterization. Expert Rev Cardiovasc Ther 2012;10:627-34.

2. Regueiro A, Freixa $X$, Bartolomé $Y$, et al. Successful percutaneous treatment of an arteriovenous fistula after radial primary percutaneous coronary intervention. JACC Cardiovasc Interv 2014;7:e123-e124. 